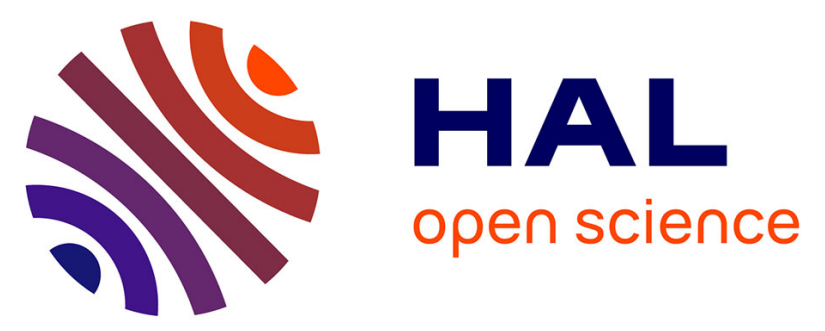

\title{
Performance Assessment of a 3D Hydrodynamic Model Using High Temporal Resolution Measurements in a Shallow Urban Lake
}

Frédéric Soulignac, Brigitte Vinçon-Leite, Bruno J. Lemaire, José Scarati

Martins, Céline Bonhomme, Philippe Dubois, Yacine Mezemate, Ioulia

Tchiguirinskaia, Daniel Schertzer, Bruno Tassin

\section{To cite this version:}

Frédéric Soulignac, Brigitte Vinçon-Leite, Bruno J. Lemaire, José Scarati Martins, Céline Bonhomme, et al.. Performance Assessment of a 3D Hydrodynamic Model Using High Temporal Resolution Measurements in a Shallow Urban Lake. Environmental Modeling \& Assessment, 2017, 22 (4), pp.309-322. 10.1007/s10666-017-9548-4 . hal-01770079

\section{HAL Id: hal-01770079 \\ https: / hal-enpc.archives-ouvertes.fr/hal-01770079}

Submitted on 7 May 2018

HAL is a multi-disciplinary open access archive for the deposit and dissemination of scientific research documents, whether they are published or not. The documents may come from teaching and research institutions in France or abroad, or from public or private research centers.
L'archive ouverte pluridisciplinaire HAL, est destinée au dépôt et à la diffusion de documents scientifiques de niveau recherche, publiés ou non, émanant des établissements d'enseignement et de recherche français ou étrangers, des laboratoires publics ou privés. 


\section{Performance Assessment of a 3D Hydrodynamic Model Using High Temporal Resolution Measurements in a Shallow Urban Lake}

Frédéric Soulignac, Brigitte Vinçon-Leite, Bruno J. Lemaire, José R. Scarati Martins, Céline Bonhomme, Philippe Dubois, Yacine Mezemate, Ioulia Tchiguirinskaia, Daniel Schertzer, Bruno Tassin

\section{Introduction}

Urban lakes provide many ecosystem services: regulation services (flood control, biodiversity conservation, coolness island), cultural services (recreational activities, angling, tourism, education), and ecological services (nature protection areas). At a global scale, the vast majority of lakes has an area smaller than $1 \mathrm{~km}^{2}$. Taking into account the very small lakes $\left(\leq 0.001 \mathrm{~km}^{2}\right)$, the total area of lakes was estimated between $3.110^{6} \mathrm{~km}^{2}[\underline{1}]$ and 4.2 $10^{6} \mathrm{~km}^{2}$ [2]. In urban areas, the lakes are predominantly small and shallow. For instance, in the Île-de-France region around Paris, the number of lakes and ponds of surface larger than $0.01 \mathrm{~km}^{2}$ is estimated around 990 [ 3 ], but $99 \%$ of them are very small, with an area lower than $0.5 \mathrm{~km}^{2}$, the minimum area of the lakes monitored in the frame of the European Water Framework Directive.

Whereas large, deep lakes of long water time residence integrate the dynamics of weather and their tributaries over seasonal time scale, shallow lakes can strongly react within a few hours. The meteorological forcing affects the greater part of the water column. Their smaller stability can more easily be overruled by air cooling or by the momentum brought by wind or inflows, causing the alternation of periods of thermal stratification and mixing. These lakes are called polymictic as opposed to the monomictic or dimictic deep lakes. In particular, summer mixing episodes cause the transfer of heat flux to the lake bottom and high vertical velocities close to the bottom favoring sediment resuspension leading to nutrient release and increased turbidity [4]. The spatial distribution of the external forces can be very heterogeneous: local stormwater input, differential shadowing by the surrounding buildings, heterogeneous bottom roughness due to submersed macrophytes and artificial bottom. Therefore, the hydrodynamic processes in shallow lakes are complex.

Hydrodynamics strongly affect the distribution of water quality components and ecological processes. In many cases, the goal of 3D modeling is to understand and predict the water quality evolution of a lake in response to changing external pressures: climate forcing, nutrient loading, and pollutant input $[\underline{5}, \underline{6}, \underline{7}]$. The hydrodynamic sub-model is a tool aimed at providing the spatial water temperature distribution, the water current field, and the spatial patterns of mixing to the coupled water quality model. Three-dimensional numerical modeling is a compulsory tool in order to understand the hydrodynamic behavior of shallow lakes and its influence on the fate of pollutants and ecosystem functioning, but also to interpret the results of discrete chemical and biological campaigns since lake conditions may vary considerably between the campaigns. But hydrodynamics of small and shallow lakes are less studied than in large lakes and 3D modeling attempts are rare.

In small shallow lakes at intermediate latitudes, current velocities are generally very low ( $\mathrm{mm} \mathrm{s}^{-1}$ to $\mathrm{cm} \mathrm{s}^{-1}$ ). The acquisition of such low velocities demands high sensitivity current meters [ $\underline{8}$ ]. The scarcity of this type of data frequently limits the validation of three-dimensional (3D) hydrodynamic models and therefore their practical applicability [9]. More generally, in order to understand the hydrodynamic behavior of these lakes, high resolution and high frequency measurements are necessary. Indeed, a survey of scientific references performed on Web of Science in April 2016 with the key words "hydrodynamic model" (topic) and "large lake*" (title) against "hydrodynamic model" and "small lake*" showed that there are about 5 times more papers on the modeling of large lakes than small lakes, respectively 34 versus 6.

In this study, we present the first validation of a 3D hydrodynamic model on a small shallow lake, Lake Créteil, France, with high resolution and high frequency measurements. Our objective was to assess the model performance: can it reproduce the alternation of thermal stratification and mixing, internal waves and spatial heterogeneities of current speed and water temperature? We present the calibration of the model on a 1-month period with continuous water temperature measurements and current speed profiles. We then present the model performance assessment on the same variables as well as on the net heat flux at the surface and water temperature at two other measuring points for 18 periods of around a month, from May 2012 to January 2014. The model capability to describe correctly the alternation of mixing and stratification periods is also discussed.

\section{Material and Methods}

\subsection{Study Site}

Lake Créteil is located in an urbanized area in the south-east of Paris, France (Fig. 1). Its area is $0.4 \mathrm{~km}^{2}$, its perimeter $4 \mathrm{~km}$, its length $1.5 \mathrm{~km}$, its width varies between 250 and $400 \mathrm{~m}$. Its mean depth is $4.5 \mathrm{~m}$, with a 
maximum of $6.5 \mathrm{~m}$, and its volume is $1.910^{6} \mathrm{~m}^{3}$. The northern part is shallower than the southern part. The lake was created as an extraction quarry of gravel and gypsum between 1940 and 1976 and was dug in the former alluvium of the Seine river, near its confluence with the Marne river [10]. The quarry was transformed into an urban lake in the middle of the 1970s; it includes a recreation center of Île-de-France regional council with a park of $0.62 \mathrm{~km}^{2}$ on the lake's western bank. The lake is surrounded by buildings in the North, East, and South-East. The lake is fed by groundwater which flows mainly from the Marne river to the Seine river due to a $1 \mathrm{~m}$ difference in the normal level of the navigation reaches, by storm water from a $1 \mathrm{~km}^{2}$ urbanized area in the East and by direct precipitation. The water level is regulated by a fixed gate on the western bank. The lake is used for recreational activities (boating, sailing, angling, etc.), to water the park on the western bank, to clean the roads, and for roadwork.
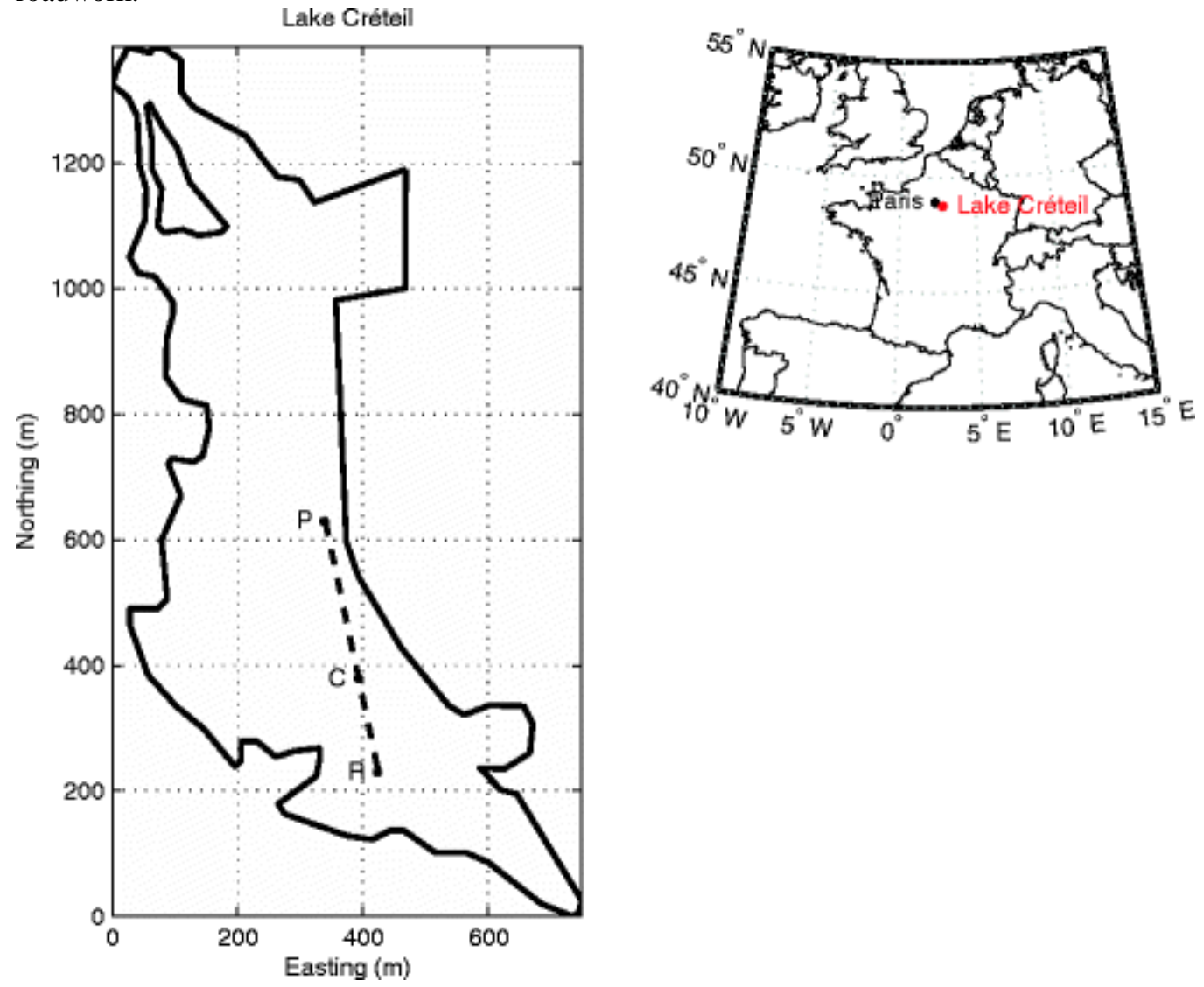

Fig. 1

Location of Lake Créteil and of the measuring points $\mathrm{P}$ close to the storm water inlet, $\mathrm{C}$ in a more central location, and $\mathrm{R}$ close to the lake outlet

\subsection{Measuring Equipment and Database}

A transmitting monitoring buoy equipped with a meteorological station and a sensor chain as well as two other sensor chains were installed in Lake Créteil in May 2012. They measured continuously vertical profiles and horizontal transects of water temperature in the lake over 21 months.

The monitoring buoy (Precision Measurement Engineering Environmental Sensor Platform, LakeESP) was moored in the deepest region of the lake at point C (Fig. 1) and has worked continuously since May 11, 2012. The meteorological station, located $2 \mathrm{~m}$ above the lake surface, measures wind speed and direction, liquid precipitation, barometric pressure, air temperature, relative humidity (Vaisala Weather Transmitter WXT520), and net total radiation (Kipp and Zonen NR Lite2). The underwater chain is equipped with five temperature sensors (accuracy $0.01^{\circ} \mathrm{C}$ ). The sampling time-step is $30 \mathrm{~s}$. The sensors are located at fixed heights above the lake bottom which correspond to average depths of $0.5,1.5,2.5,3.5$, and $4.5 \mathrm{~m}$.

Two other sensor chains were also installed on buoys on October 25, 2012. One is located at point $\mathrm{P}$ in front of the municipal storm-water inlet and the other at point $\mathrm{R}$ in the southern part of the lake near a reed bed and the lake outlet (Fig. 1). The three points $\mathrm{P}, \mathrm{C}$, and $\mathrm{R}$ are aligned with $250 \mathrm{~m}$ between $\mathrm{P}$ and $\mathrm{C}$ and $150 \mathrm{~m}$ between $\mathrm{C}$ and R. These additional chains are composed of two temperature sensors (nke Instrumentation SP2T) at 0.5 and $2.5 \mathrm{~m}$ depths and one multiparameter probe (nke Instrumentation MP5) which measures water temperature 
(accuracy $0.01^{\circ} \mathrm{C}$ ), dissolved oxygen and chlorophyll fluorescence at $1.5 \mathrm{~m}$ depth. Variables are sampled every 30 $\mathrm{s}$ as on the central measuring station.

A high-resolution current profiler ( $2 \mathrm{MHz}$ Nortek Aquadopp) was mounted head upwards on an rigid aluminum frame near the central measuring station at point C from September 17, 2013 to October 15, 2013. The velocity profiles were sampled every $3 \mathrm{~m}$ and spread from 4.5 to $1.5 \mathrm{~m}$ depth with a vertical resolution of $2.3 \mathrm{~cm}$.

Bathymetry was measured in September 2014 with an echo-sounder (HumminBird 798ci HD SI Combo).

Between 14 May 2012 and 17 January 2014, the water transparency was measured monthly at points P, C, and R with a Secchi disk.

\subsection{Model Configuration}

The 3D hydrodynamical model Delft3D-FLOW was used. It solves the Navier-Stokes equations for an incompressible fluid, under the shallow water and the Boussinesq assumptions. The system of equation consists of the continuity equation (Eq. 1), the two horizontal equations of motion (Eqs. $\underline{2}$ and $\underline{3}$ ), the equation of motion in the vertical direction being reduced to the hydrostatic pressure equation, and the transport equation of heat (Eq. 4). This set of partial differential equations in combination with an appropriate set of initial and boundary conditions is solved on a finite difference grid with current velocities defined on cell faces and scalar variables at cell centres. Delft3D-FLOW was fully described in the user manual [11]. Here, we present the model configuration we used.

$$
\begin{aligned}
& \frac{\partial u}{\partial x}+\frac{\partial v}{\partial y}+\frac{\partial w}{\partial z}=0 \\
& \frac{\partial u}{\partial t}+u \frac{\partial u}{\partial x}+v \frac{\partial u}{\partial y}+w \frac{\partial u}{\partial z} \\
= & -\frac{1}{\rho_{0}} \frac{\partial p}{\partial x}+\frac{\partial}{\partial x}\left(\nu_{H} \frac{\partial u}{\partial x}\right)+\frac{\partial}{\partial y}\left(\nu_{H} \frac{\partial u}{\partial y}\right)+\frac{\partial}{\partial z}\left(\nu_{V} \frac{\partial u}{\partial z}\right) \\
& \frac{\partial v}{\partial t}+u \frac{\partial v}{\partial x}+v \frac{\partial v}{\partial y}+w \frac{\partial v}{\partial z} \\
= & -\frac{1}{\rho_{0}} \frac{\partial p}{\partial y}+\frac{\partial}{\partial x}\left(\nu_{H} \frac{\partial v}{\partial x}\right)+\frac{\partial}{\partial y}\left(\nu_{H} \frac{\partial v}{\partial y}\right)+\frac{\partial}{\partial z}\left(\nu_{V} \frac{\partial v}{\partial z}\right) \\
& \frac{\partial T}{\partial t}+u \frac{\partial T}{\partial x}+v \frac{\partial T}{\partial y}+w \frac{\partial T}{\partial z} \\
= & \frac{\partial}{\partial x}\left(D_{H} \frac{\partial T}{\partial x}\right)+\frac{\partial}{\partial y}\left(D_{H} \frac{\partial T}{\partial y}\right)+\frac{\partial}{\partial z}\left(D_{V} \frac{\partial T}{\partial z}\right)+\frac{S}{\rho_{0} c_{p w}}
\end{aligned}
$$

$x, y$, and $z$ are Cartesian coordinates $(\mathrm{m}) . t$ is time (s). $u, v$, and $w$ are the three components of the water velocity $\left(\mathrm{m} \mathrm{s}^{-1}\right) . T$ is the water temperature $(\mathrm{K}), \rho_{0}$ is the water density $\left(\mathrm{kg} \mathrm{m}^{-3}\right)$ and $p$ is the pressure $(\mathrm{Pa}) . v_{H}$ and $v_{V}$ are the horizontal and vertical eddy viscosities $\left(\mathrm{m}^{2} \mathrm{~s}^{-1}\right) . D_{H}$ and $D_{V}$ are the horizontal and vertical coefficients of eddy diffusivity of heat $\left(\mathrm{m}^{2} \mathrm{~s}^{-1}\right) . S$ is the source of heat per unit volume $\left(\mathrm{W} \mathrm{m}^{-3}\right)$ and $c_{p}{ }_{w}$ is the water specific heat $(\mathbf{J}$ $\mathrm{K}^{-1} \mathrm{~kg}^{-1}$ ). Molecular viscosity and diffusivity are neglected.

The horizontal surface of the lake was meshed with 981 Cartesian cells of $20 \mathrm{~m}$ x $20 \mathrm{~m}$. In order to obtain a good simulation of the water column stratification, the Z-model was used with 18 layers of $33 \mathrm{~cm}$. The sensor depths correspond to cell centers. Too thin bottom layers were remapped automatically in order to better represent the current speed close to the bottom.

The eddy viscosity and diffusivity of heat are anisotropic. In the vertical direction, the eddy viscosity $v{ }_{V}$ and the eddy diffusivity of heat $D_{V}$ were calculated using the k- turbulence closure model. Two parameters are used in Delft3D-FLOW to reproduce subgrid horizontal motions and fluxes, the background (minimum) values of the horizontal eddy viscosity vbackHvHback and diffusivity of heat DbackHDHback. We used as fixed values for these parameters the time and space averages of the eddy viscosity and diffusivity of heat computed by 2D horizontal large eddy simulation on the calibration period (Table 1 ). The time and space averages of the eddy viscosity and diffusivity of heat computed by $2 \mathrm{D}$ horizontal large eddy simulation on the calibration period were then used as fixed parameters for the 3D simulations. 
Table 1

Equations of Delft3D-FLOW in the used configuration

Turbulence model

\begin{tabular}{ll}
\hline$\nu_{H}=\nu_{V}+\nu_{H}^{\text {back }}, D_{H}=D_{V}+D_{H}^{\text {back }}, v_{V}=v_{m o l}+v_{3} D, D_{V}=\frac{\nu_{\text {mad }}}{\sigma_{\mathrm{mod}}}+D_{3 D}$ \\
\hline$v_{H}$ & Horizontal eddy viscosity $\left(\mathrm{m}^{2} \mathrm{~s}^{-1}\right)$ \\
\hline$v_{V}$ & Vertical eddy viscosity $\left(\mathrm{m}^{2} \mathrm{~s}^{-1}\right)$ \\
\hline$\nu_{H}^{\text {back }}$ & Background horizontal eddy viscosity $\left(\mathrm{m}^{2} \mathrm{~s}^{-1}\right)$ \\
\hline$v_{m o l}$ & Water kinematic viscosity $\left(10^{-6} \mathrm{~m}^{2} \mathrm{~s}^{-1}\right)$ \\
\hline$v_{3 D}$ & Turbulent viscosity calculated by the $\mathrm{k}-\epsilon$ turbulence closure model $\left(\mathrm{m}^{2} \mathrm{~s}^{-1}\right)$ \\
\hline$D_{H}$ & Horizontal eddy diffusivity of heat $\left(\mathrm{m}^{2} \mathrm{~s}^{-1}\right)$ \\
\hline$D_{V}$ & Vertical eddy diffusivity of heat $\left(\mathrm{m}^{2} \mathrm{~s}^{-1}\right)$ \\
\hline$D_{H}^{\text {back }}$ & Background horizontal eddy diffusivity of heat $\left(\mathrm{m}^{2} \mathrm{~s}^{-1}\right)$ \\
\hline$\sigma_{m 0 l}$ & Prandtl number for heat diffusion $(0.7)$ \\
\hline$D_{3 D}$ & Turbulent diffusivity of heat calculated by the turbulence model $\left(\mathrm{m}^{2} \mathrm{~s}^{-1}\right)$ \\
\hline
\end{tabular}

Flow boundary conditions

\begin{tabular}{ll}
\hline$\tau_{s}=\rho_{a} C_{d}|\mathbf{U}| \mathbf{U}, \tau_{\mathbf{b}}=\frac{g \rho_{a} n^{2}\left|\mathbf{u}_{\mathbf{b}}\right| \mathbf{u}_{\mathbf{b}}}{H^{\frac{1}{3}}}$ \\
\hline$\tau_{s}$ & Shear stress at the lake surface $(\mathrm{Pa})$ \\
\hline$\rho_{a}$ & Air density $\left(1.2 \mathrm{~kg} \mathrm{~m}^{-3}\right)$ \\
\hline $\mathbf{U}$ & Wind speed vector $\left(\mathrm{m} \mathrm{s}^{-1}\right)$ \\
\hline$C_{d}$ & Wind drag coefficient, a calibration parameter $(-)$ \\
\hline$\tau_{b}$ & Gravity acceleration ( $\left.9.81 \mathrm{~m} \mathrm{~s}^{-2}\right)$ \\
\hline$g$ & Current velocity vector in the layer above the bottom $\left(\mathrm{m} \mathrm{s}^{-1}\right)$ \\
\hline$u_{b}$ & Manning's friction coefficient (s m $\left.\mathrm{m}^{-1 / 3}\right)$ \\
\hline$n$ & Local water depth (m)
\end{tabular}

Lake surface heat flux model

\begin{tabular}{ll}
\hline$Q_{e v, f o r c e d}=L_{V} \rho_{a} c_{e} U\left(q_{s}-q_{a}\right), Q_{c o, f o r c e d}=\rho_{a} c_{p a} c_{H} U\left(T_{s}-T_{a}\right)$ \\
\hline$L_{V}$ & Latent heat of vaporisation $(\mathrm{J} \mathrm{kg} \mathrm{-1)}$ \\
\hline$c_{e}$ & Dalton number (-) \\
\hline$q_{s}$ & Specific humidity of saturated air (-) \\
\hline$q_{a}$ & Air specific humidity (-) \\
\hline$c_{p a}$ & Stanton number (-) \\
\hline$c_{H}$ & Water surface temperature (K) \\
\hline$T_{s}$ & Air temperature (K) \\
\hline$T_{a}$ & Evaporative heat flux (latent heat, $\left.W \mathrm{~m}^{-2}\right)$ \\
\hline$Q_{e v, \text { forced }}$ & Convective heat flux (sensible heat, $W \mathrm{Km}^{-2}$ )
\end{tabular}


This configuration enabled to prescribe different levels of turbulence in vertical and horizontal directions. A sensitivity analysis on the mean absolute error (MAE) of water temperature showed that no additional mixing was necessary: we left the Ozmidov length $L_{z}$ parameter which triggers mixing at the thermocline, the background vertical eddy viscosity, and the background vertical eddy diffusivity of heat to their default value, zero.

The shear stress at the surface of the lake due to the wind was modeled with a constant wind drag coefficient, a calibration parameter (Table 1 ). The shear stress at the bottom of the lake was modeled with the Manning formulation. A value of $0.02 \mathrm{~s} \mathrm{~m}-13-13$ was adopted for the Manning coefficient because the bottom of the lake, a former gravel quarry, is smooth. The vertical wall roughness of the banks was neglected.

Heat fluxes through the banks and the lake bottom were neglected. The heat surface model that we chose to use was adapted from Gill [12]. The latent heat flux by forced convection is parameterized by the Dalton number $c_{e}$, the sensible heat flux by forced convection, by the Stanton number $c_{H}$, and the latent and sensible heat fluxes by free convection, by the coefficient of free convection $C F r C o n$ (Table 1 ). These coefficients were calibrated for the North Sea [13] and applied successfully for Lake Créteil.

In the water column, light dampens according to Beer-Lambert law. The extinction coefficient was considered as a calibration parameter. We verified that its value is close to the extinction coefficient calculated from the water transparency measurements (Secchi depth).

The water density was calculated according to UNESCO formulation [14] with a salinity of 0.75 ppt corresponding to the observed specific conductance of $1500 \mu \mathrm{S} \mathrm{cm}^{-1}$. This relatively high salinity is due to the geological calcocarbonated nature of the catchment.

Water level variations were neglected; they never exceeded $3 \%$ of the water height over a simulation period.

Simulations were initialized with water temperature observed at the measuring station on the first day of the simulation. The water was supposed to be at rest, an usual assumption in 3D hydrodynamic simulation. Simulations were started and stopped at midday. Thirty-second wind direction and speed, air temperature, relative humidity, and precipitation recorded at point $\mathrm{C}$ and hourly incident solar radiation and cloud cover measured at the nearest weather station located at Orly Airport, $10 \mathrm{~km}$ west of the lake were used to force the simulations.

An explicit time integration method was used. The computational time step was set equal to that of the meteorological variables, $30 \mathrm{~s}$. This value respects the Courant-Friedrichs-Levy stability criterion. The equation of momentum is solved by a multidirectional upwind explicit numerical scheme and the equation of heat by the second Van Leer numerical scheme.

The total net radiation through the lake surface, sum of the incident solar radiation reduced from albedo, the net atmospheric radiation, and the back radiation of the lake surface was computed separately with Delft3D-FLOW equations in order to compare the simulated values to the measurements.

\subsection{Model Calibration and Performance Assessment}

A period of 28 days between between 17 September 2013 and 15 October 2013 was chosen for calibration because this period presented a full stratification and also all measurements were available, including current profiles. Only two parameters, the wind drag coefficient and the light extinction coefficient, were calibrated. The trial and error method was used to calibrate these parameters in order that simulated profiles of hourly water temperature and current velocity at point $C$ best fitted observations. The MAE was used as performance indicator. Simulated and observed hourly total net radiation at the lake surface and water temperature at points $\mathrm{C}, \mathrm{P}$, and $\mathrm{R}$ were compared graphically. MAE was computed for the total net radiation, at the five depths of the sensors for water temperatures at point $\mathrm{C}$ and at the three depths of the sensors for water temperatures at points $\mathrm{P}$ and $\mathrm{R}$. The hourly resolution used for this comparison is consistent with the time scale of biological processes which coupled hydrodynamicbiogeochemical simulations could later reproduce. Moreover, time averaging is required to compare the evolution of temperatures simulated in a large cell (several $\mathrm{m}^{3}$ ) to much more fluctuating temperatures measured at a point. Only graphical assessment was performed for current velocities.

The model was then run with the same set of parameters, namely the wind drag coefficient and the Secchi depth during 18 other time periods between two consecutive monthly field campaigns. They covered a wide range of hydrodynamic situations in the lake and of meteorological forcing. For each simulation period, the measured temperature profiles were used as initial conditions. Comparison between observed and simulated values was performed as described for calibration. For synthesizing multiple aspects of the model performance, we used a 
single diagram, the Taylor diagram [15]. This diagram provides a summary of two statistical indicators of model performance: the linear correlation coefficient between model results and observed values and the ratio of standard deviations of simulated and measured values. A global skill index was also computed.

\section{Results}

This section presents first the results of model calibration based on the discrepancies between model results and measurements of water temperature and speed at point $\mathrm{C}$, of stratification duration and dates and of the characteristics of the internal waves (amplitude and frequency). The model verification is then presented based on the same criteria for 18 simulation periods of around 1 month, from May 2012 to January 2014.

\subsection{Model Calibration}

The calibration period was chosen between 17 September and 15 October 2013 (28 days). The number of layers was set to 18 corresponding to a layer thickness of $33 \mathrm{~cm}$. With a higher thickness, the velocities under the thermocline became much lower than measured. Only the drag coefficient and the Secchi depth were calibrated (Table 2). Values of wind drag coefficient ranging between 0 and $10^{-2}$ were tested. Finally, the wind drag coefficient was set to 0.0015. For this value, average MAE of water temperature was lowest and the model reproduced best the current speeds and the amplitudes of internal waves. A Secchi depth of $1 \mathrm{~m}$ close to the one observed during the calibration period, corresponding to an extinction coefficient of $1.7 \mathrm{~m}^{-1}$, was adopted to reproduce properly the temperature differences between surface $(0.5 \mathrm{~m}$ depth$)$ and bottom $(4.5 \mathrm{~m})$ sensors.

\section{Table 2}

Comparison of mesh characteristics and parameter values used for simulations with Delft3D-FLOW on different lakes (nc: not communicated, na: not applicable)

\begin{tabular}{|c|c|c|c|c|}
\hline & $\begin{array}{l}\text { This } \\
\text { study }\end{array}$ & $\begin{array}{l}\text { Wahl et al. } \\
2014\end{array}$ & $\begin{array}{l}\text { Chanudet et al. } \\
2012\end{array}$ & $\begin{array}{l}\text { Zhu et al. } \\
2009\end{array}$ \\
\hline Lake name & Créteil & Constance & Nam Theun 2 & Yangchenghu \\
\hline $\begin{array}{l}\text { Horizontal grid size } \\
\text { (m) }\end{array}$ & $20 \times 20$ & $350 \times 1500$ & $150 \times 150$ & $\mathrm{nc}$ \\
\hline $\begin{array}{l}\text { Number of layers } \\
(-)\end{array}$ & 18 & 50 & 25 & 10 \\
\hline$\nu_{H}^{\text {back }}\left(\mathrm{m}^{2} \mathrm{~s}^{-1}\right)$ & 0.01 & 10 & 2.5 & 1 \\
\hline$D_{H}^{\text {back }}\left(\mathrm{m}^{2} \mathrm{~s}^{-1}\right)$ & 0.01 & 10 & 2.5 & na \\
\hline$\nu_{V}^{\text {back }}\left(\mathrm{m}^{2} \mathrm{~s}^{-1}\right)$ & 0 & 0 & 0 & nc \\
\hline$D_{V}^{\text {back }}\left(\mathrm{m}^{2} \mathrm{~s}^{-1}\right)$ & 0 & 0 & 0 & na \\
\hline$L_{z}(\mathrm{~m})$ & o & nc & 0 & $\mathrm{nc}$ \\
\hline$C_{d}(-)$ & 0.0015 & $C_{d}(U)$ & 0.0005 & 0.0025 \\
\hline$c_{e}(-)$ & 0.0015 & 0.0021 & 0.0016 & na \\
\hline$c_{H}(-)$ & 0.00145 & 0.00145 & 0.0016 & na \\
\hline $\operatorname{cFrCon}(-)$ & 0.14 & nc & nc & na \\
\hline$S_{d}(\mathrm{~m})$ & 1 & 4 & nc & na \\
\hline
\end{tabular}

Hourly means of simulated and observed water temperature and horizontal current velocity at point $\mathrm{C}$ between 17 September and 15 October 2013 are plotted on Fig. 2a, b. On Fig. 2 c are plotted temperature differences between points $\mathrm{P}$ and $\mathrm{R}$. The temperature evolution is well reproduced (MAE of hourly temperature during the simulation and over the five depths is $0.48^{\circ} \mathrm{C}$ ), as well as the alternation between stratification and mixing periods. The water column was mixed the first day of the simulation and the onset of the stratification was observed on 20 September 2013, whereas the simulation reproduced it one day after, on 21 September. Observed and simulated duration of stratification was respectively 16 and 15 days. The end of stratification was reproduced by the model at the correct 
date on 5 October 2013. The simulated current speeds are very close to the observed ones (Fig. 2 b) as well as the temperature differences between points $\mathrm{P}$ and $\mathrm{R}$ (Fig. 2 c). The capacity of the model to reproduce the low velocity values in the layers below the thermocline during stratification must be highlighted. Internal waves are observed in Lake Créteil during stratification periods. An intense internal wave activity was observed during the calibration period, between 28 to 30 September 2013 when a strong wind episode occurred. The observed internal wave patterns showed a period of $17 \mathrm{~h}$ and a maximum temperature variation of $1.5^{\circ} \mathrm{C}$ from peak to peak at $2.5 \mathrm{~m}$ depth. These high fluctuations of water temperature at $2.5 \mathrm{~m}$ depth are well reproduced and the period of $17 \mathrm{~h}$ was also captured by the model.
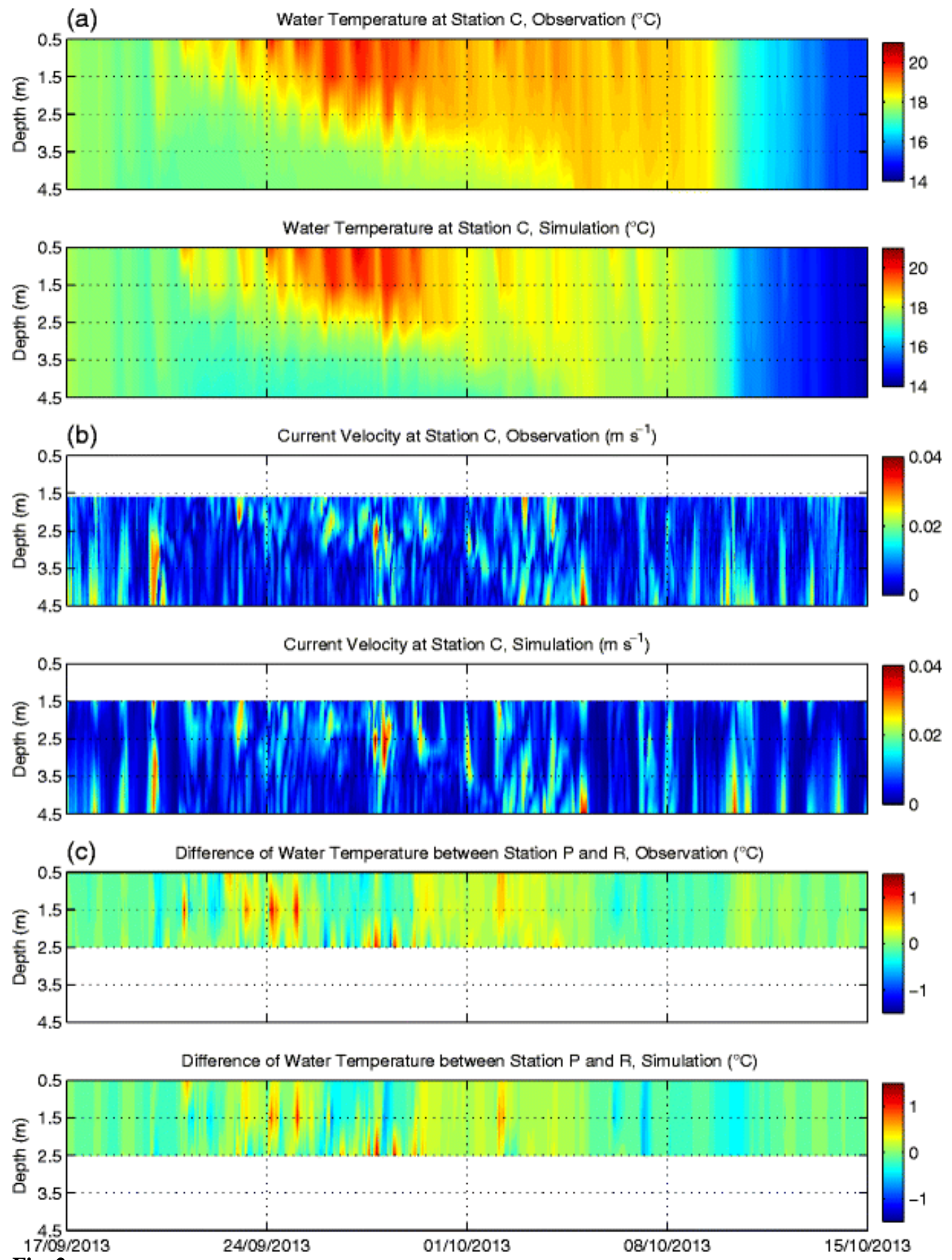

Fig. 2

Calibration period: Hourly mean profiles of observed and simulated water temperature at point $\mathrm{C}$ (a), horizontal current velocity at point $\mathrm{C}$ (b), and difference of water temperature between points $\mathrm{P}$ and $\mathrm{R}(\mathbf{c})$, between 17/09 and 
15/10/2013 (observed water temperature at point $C$ and temperature differences are linearly interpolated between the five measurement depths $(0.5,1.5,2.5,3.5$, and $4.5 \mathrm{~m})$, the vertical resolution of the velocity profile is $2.3 \mathrm{~cm}$, the simulated values are linearly interpolated at the centre depth of the 18 computational layers)

\subsection{Model Verification}

Nineteen simulations were run over the period from 14 May 2012 to 17 January 2014 including the calibration period. The length of these simulations was about 1 month. Measurements and simulation results of total net radiation through the lake surface at point $\mathrm{C}$ and water temperature at points $\mathrm{P}, \mathrm{C}$, and $\mathrm{R}$ were compared.

Hourly values of total net radiation varied between -200 and $900 \mathrm{~W} \mathrm{~m}^{-2}$, and the daily accumulation of total net radiation varied between -100 and $250 \mathrm{~W} \mathrm{~m}^{-2}$. Observations were well reproduced during the calibration period between 17 September 2013 and 15 October 2013. For the 19 simulation periods, MAE between observed and simulated total net radiations were calculated. They range between 9.9 and $25.7 \mathrm{~W} \mathrm{~m}^{-2}$. Relative MAE are smaller from spring to autumn than in winter. It means that the combination of data used as forcing meteorological variables and the formulation of the radiation part of the heat flux in the model work well.

The capability of the model to reproduce the water temperature and the alternation between stratification and mixing was assessed. Several stratifications were observed during the study period and their length ranged from a few hours up to 40 days. The longest stratification period occurred between 30 June and 8 August 2013. The alternation between stratification and mixing was very well reproduced by the model. The maximal water temperature of $27.6^{\circ} \mathrm{C}$ was observed in July 2013 and the minimum of $2.7^{\circ} \mathrm{C}$ was observed in January 2013 . Short inverse stratifications were indeed observed. Observed and simulated water temperature at point $\mathrm{C}$ are plotted for the 19 simulations (Figs. $\underline{3}$ and $\underline{4}$ ). Temperature MAE at point $\mathrm{C}$ are presented in Table $\underline{3}$ and temperature MAE at points $\mathrm{P}$ and $\mathrm{R}$ are presented in Table 4 . Plots and MAE showed that the model reproduced well the water temperature at the three points. Water temperature was better reproduced between May and October (spring, summer, and early autum) 2012 and 2013 than between October 2012 and March 2013 (late autumn and winter): Temperature MAE at point $\mathrm{C}$ over the five depths between March and October 2013 is $0.44{ }^{\circ} \mathrm{C}$ and between October 2012 and March 2013 it is $1.41^{\circ} \mathrm{C}$. An overview of the model performance is provided by Taylor diagrams (Fig. 5). These diagrams present the model performance at five depths, $0.5,1.5,2.5,3.5$, and $4.5 \mathrm{~m}$, for 19 simulation periods. Two metrics are considered for assessing the agreement between model and observations: the linear correlation coefficient $r$ and the standard deviation ratio $\sigma^{*}$. For all considered periods except period 8, from spring to autumn, at all depths, the results are excellent and very similar with high correlation coefficients and good standard deviation ratio. The global skill index indicated by the isoline area is close to 1, its maximum value. In winter, the model performance is lower. During period 8, from 10 December 2012 to 15 January 2013, low performance indicators are obtained at all depths. 

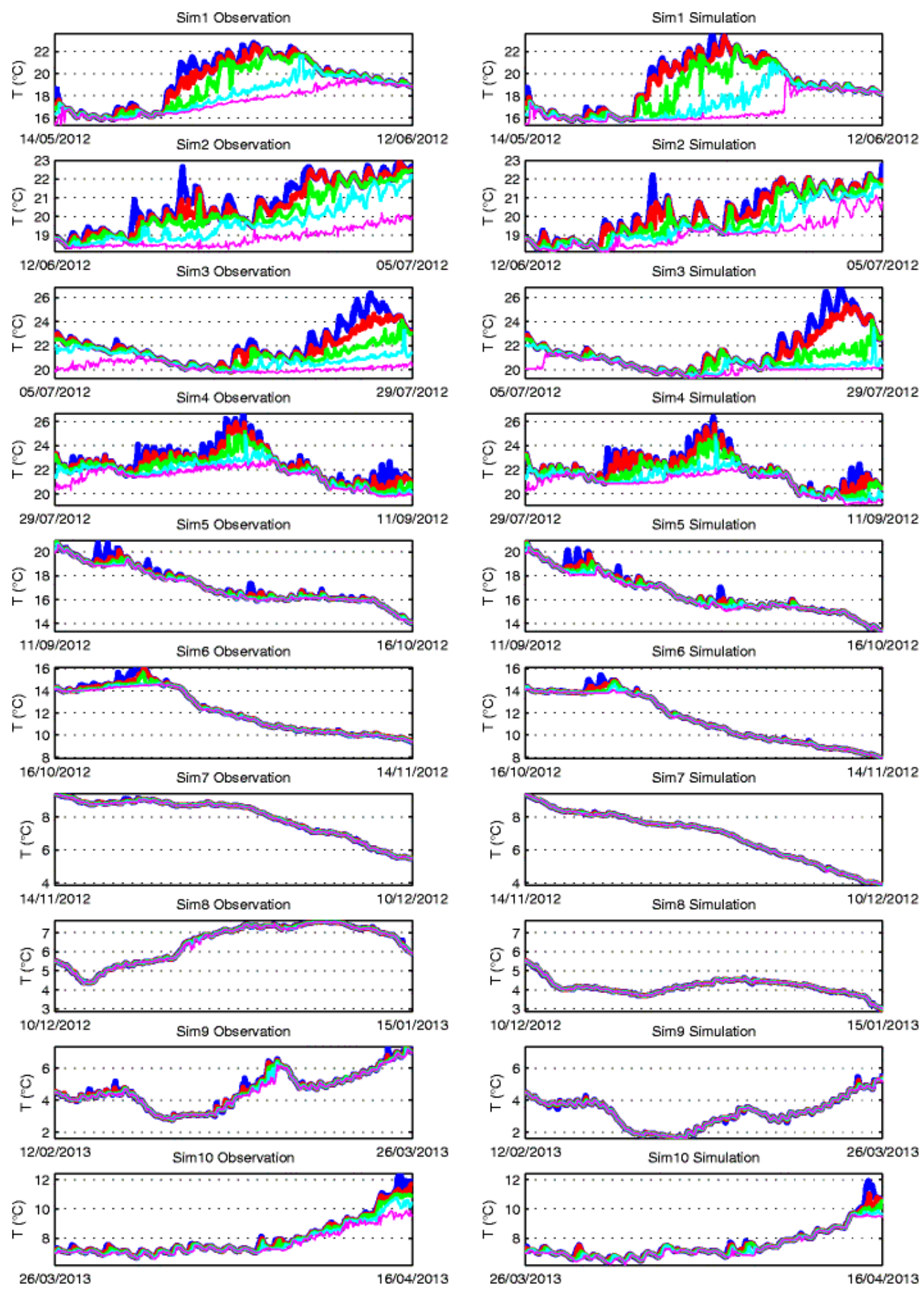

Fig. 3

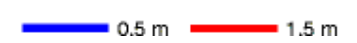

$-2.5 \mathrm{~m}$

$-3.5 \mathrm{~m}$ $4.5 \mathrm{~m}$

Observed and simulated water temperature at point $\mathrm{C}$ for simulation 1 to 10 

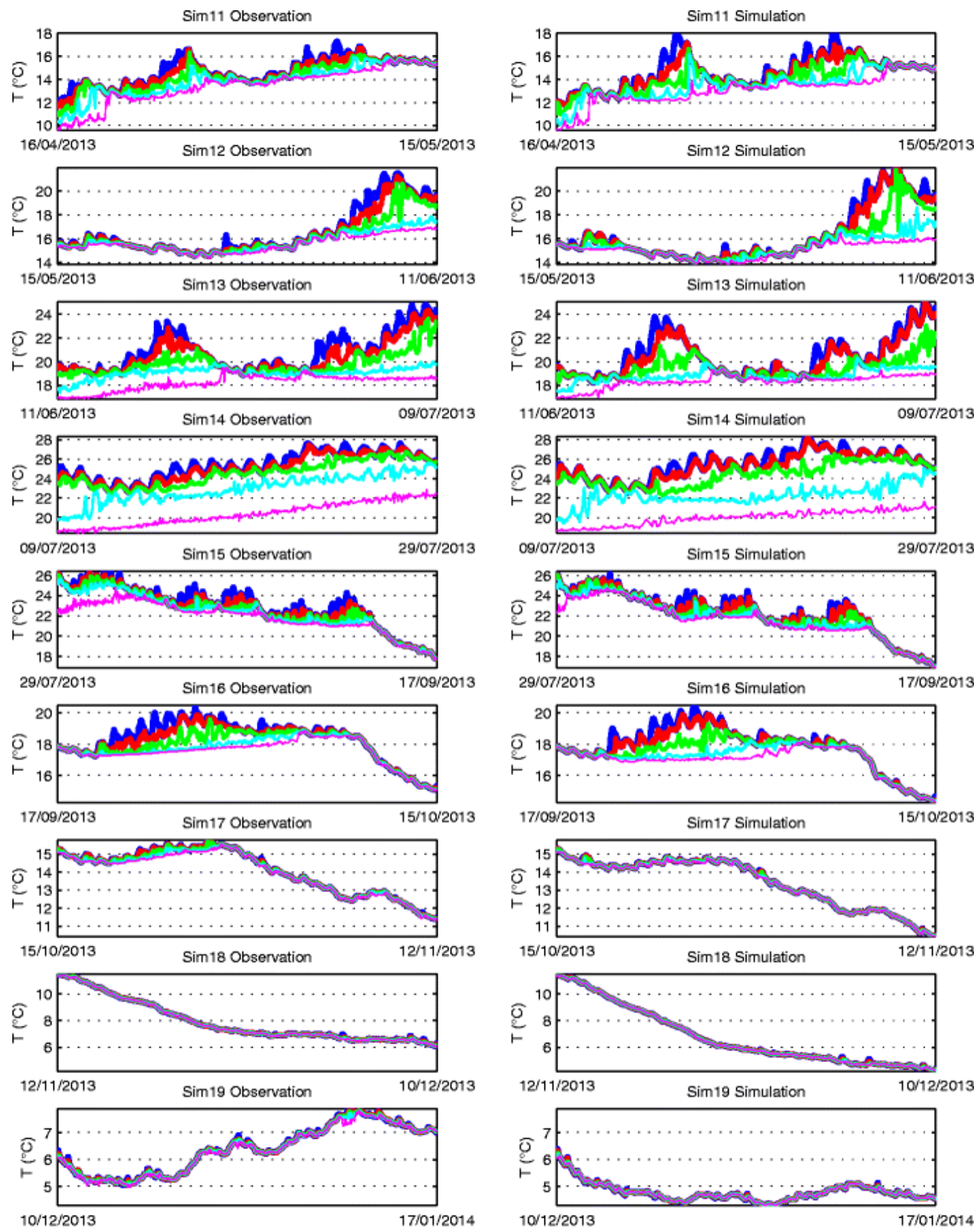

Fig. 4

Observed and simulated water temperature at point $\mathrm{C}$ for simulation 11 to 19 

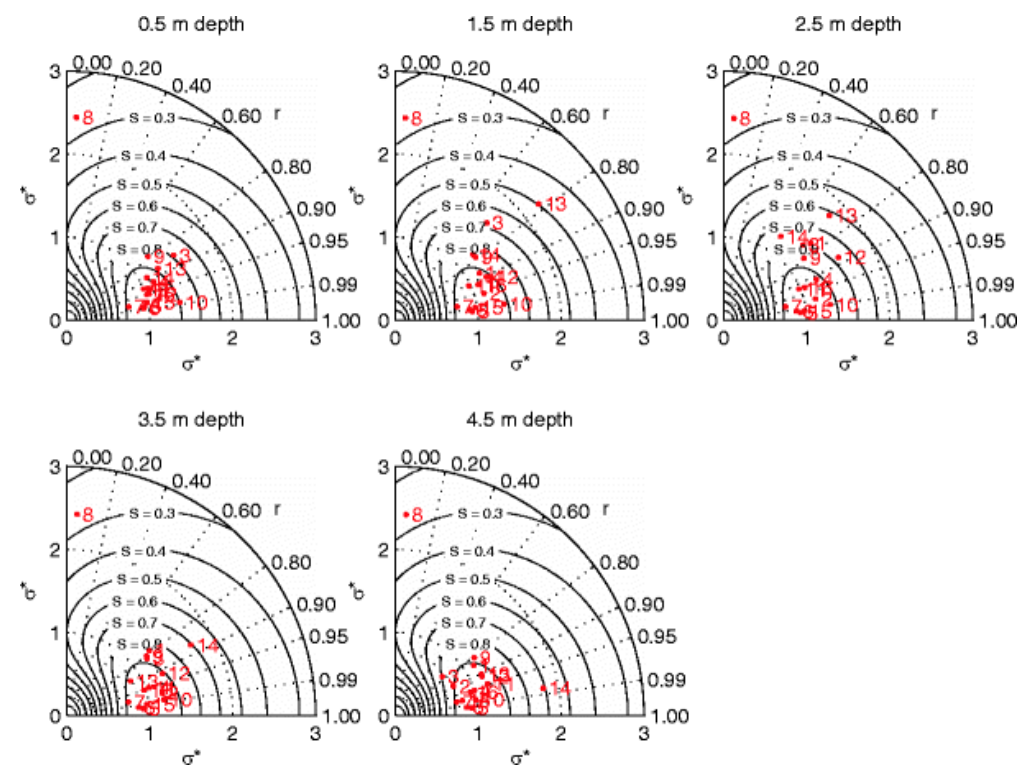

Fig. 5

Taylor diagrams of the model performance at point $\mathrm{C}$, at 5 depths, $0.5,1.5,2.5,3.5$, and $4.5 \mathrm{~m}$ depth, for 19 simulation periods (the angle $C$ corresponds to the linear correlation coefficient between model results and measurements, the $x$-axis and the $y$-axis to the ratio of standard deviations of simulated and measured values, $\sigma^{*}$ )

\section{Table 3}

Mean absolute error (MAE) of water temperature in॰ $\mathrm{C}$ at point $\mathrm{C}$ and 5 depths $(0.5,1.5,2.5,3.5$, and $4.5 \mathrm{~m})$ for the 19 simulations. Period 16 is the calibration period

\begin{tabular}{|l|l|l|l|l|l|l|l|}
\hline Sim. & Start & Stop & $\mathbf{0 . 5} \mathbf{~ m}$ & $\mathbf{1 . 5} \mathbf{~ m}$ & $\mathbf{2 . 5} \mathbf{~ m}$ & $\mathbf{3 . 5} \mathbf{~ m}$ & $\mathbf{4 . 5} \mathbf{~ m}$ \\
\hline 1 & $14 / 05 / 2012$ & $12 / 06 / 2012$ & 0.44 & 0.44 & 0.49 & 0.69 & 0.81 \\
\hline 2 & $12 / 06 / 2012$ & $05 / 07 / 2012$ & 0.48 & 0.42 & 0.40 & 0.28 & 0.33 \\
\hline 3 & $05 / 07 / 2012$ & $29 / 07 / 2012$ & 0.44 & 0.43 & 0.44 & 0.44 & 0.28 \\
\hline 5 & $29 / 07 / 2012$ & $11 / 09 / 2012$ & 0.53 & 0.48 & 0.51 & 0.52 & 0.54 \\
\hline 6 & $11 / 09 / 2012$ & $16 / 10 / 2012$ & 0.66 & 0.64 & 0.64 & 0.64 & 0.67 \\
\hline 7 & $16 / 10 / 2012$ & $14 / 11 / 2012$ & 0.84 & 0.82 & 0.79 & 0.76 & 0.77 \\
\hline 8 & $14 / 11 / 2012$ & $10 / 12 / 2012$ & 1.18 & 1.17 & 1.17 & 1.16 & 1.16 \\
\hline 10 & $10 / 12 / 2012$ & $15 / 01 / 2013$ & 2.30 & 2.29 & 2.29 & 2.28 & 2.27 \\
\hline 11 & $12 / 02 / 2013$ & $26 / 03 / 2013$ & 1.44 & 1.42 & 1.39 & 1.36 & 1.34 \\
\hline 12 & $26 / 03 / 2013$ & $16 / 04 / 2013$ & 0.41 & 0.40 & 0.38 & 0.32 & 0.25 \\
\hline 13 & $16 / 04 / 2013$ & $15 / 05 / 2013$ & 0.37 & 0.32 & 0.32 & 0.44 & 0.57 \\
\hline 14 & $15 / 05 / 2013$ & $11 / 06 / 2013$ & 0.37 & 0.41 & 0.39 & 0.43 & 0.53 \\
\hline 15 & $11 / 06 / 2013$ & $09 / 07 / 2013$ & 0.45 & 0.44 & 0.45 & 0.35 & 0.29 \\
\hline 16 & $09 / 07 / 2013$ & $29 / 07 / 2013$ & 0.34 & 0.37 & 0.32 & 0.87 & 0.47 \\
\hline 17 & $29 / 07 / 2013$ & $17 / 09 / 2013$ & 0.59 & 0.53 & 0.52 & 0.50 & 0.53 \\
\hline 18 & $17 / 09 / 2013$ & $15 / 10 / 2013$ & 0.48 & 0.45 & 0.47 & 0.48 & 0.55 \\
\hline 19 & $15 / 10 / 2013$ & $12 / 11 / 2013$ & 0.67 & 0.66 & 0.64 & 0.60 & 0.57 \\
\hline
\end{tabular}


Table 4

Mean absolute error (MAE) of water temperature in ${ }^{\circ} \mathrm{C}$ at points $\mathrm{P}$ and $\mathrm{R}$ and three depths $(0.5,1.5$, and $2.5 \mathrm{~m})$ for the 19 simulations. Period 16 is the calibration period

\begin{tabular}{|l|l|l|l|l|l|l|l|l|}
\hline Sim. & Start & Stop & Point P & & Point R & \\
\hline 1 & & & $\mathbf{0 . 5} \mathbf{~ m}$ & $\mathbf{1 . 5} \mathbf{~ m}$ & $\mathbf{2 . 5} \mathbf{~ m}$ & $\mathbf{0 . 5} \mathbf{~ m}$ & $\mathbf{1 . 5} \mathbf{~ m}$ & $\mathbf{2 . 5} \mathbf{~ m}$ \\
\hline 2 & $14 / 05 / 2012$ & $12 / 06 / 2012$ & na & na & na & na & na & na \\
\hline 3 & $05 / 07 / 2012$ & $05 / 07 / 2012$ & na & na & na & na & na & na \\
\hline 4 & $29 / 07 / 2012$ & $11 / 09 / 2012$ & na & na & na & na & na & na \\
\hline 5 & $11 / 09 / 2012$ & $16 / 10 / 2012$ & na & na & na & na & na & na \\
\hline 6 & $16 / 10 / 2012$ & $14 / 11 / 2012$ & 1.01 & 1.03 & 0.98 & 0.94 & na & 0.93 \\
\hline 7 & $14 / 11 / 2012$ & $10 / 12 / 2012$ & 1.24 & 1.26 & 1.22 & 1.12 & na & 1.12 \\
\hline 8 & $10 / 12 / 2012$ & $15 / 01 / 2013$ & 2.34 & na & 2.31 & 2.26 & na & 2.23 \\
\hline 9 & $12 / 02 / 2013$ & $26 / 03 / 2013$ & 1.47 & na & 1.37 & 1.45 & na & 1.40 \\
\hline 10 & $26 / 03 / 2013$ & $16 / 04 / 2013$ & 0.52 & 0.51 & 0.48 & 0.60 & 0.57 & 0.51 \\
\hline 11 & $16 / 04 / 2013$ & $15 / 05 / 2013$ & 0.35 & 0.33 & 0.32 & 0.36 & 0.32 & 0.35 \\
\hline 12 & $15 / 05 / 2013$ & $11 / 06 / 2013$ & 0.44 & 0.47 & 0.50 & 0.43 & na & 0.47 \\
\hline 13 & $11 / 06 / 2013$ & $09 / 07 / 2013$ & 0.34 & 0.34 & 0.44 & 0.41 & 0.40 & 0.46 \\
\hline 14 & $09 / 07 / 2013$ & $29 / 07 / 2013$ & na & na & na & na & na & na \\
\hline 15 & $29 / 07 / 2013$ & $17 / 09 / 2013$ & 0.62 & 0.57 & 0.51 & 0.62 & 0.54 & 0.51 \\
\hline 16 & $17 / 09 / 2013$ & $15 / 10 / 2013$ & 0.53 & 0.49 & 0.48 & 0.49 & 0.45 & 0.44 \\
\hline 17 & $15 / 10 / 2013$ & $12 / 11 / 2013$ & 0.67 & 0.66 & 0.66 & 0.67 & 0.67 & 0.62 \\
\hline 18 & $12 / 11 / 2013$ & $10 / 12 / 2013$ & 1.21 & 1.17 & 1.21 & na & 1.15 & 1.12 \\
\hline 19 & $10 / 12 / 2013$ & $17 / 01 / 2014$ & na & na & na & na & na & na \\
\hline
\end{tabular}

\section{Discussion}

In Lake Créteil, the Delft3D model describes properly the water temperature seasonal evolution and the current speed at the center of the lake as well as the temperature difference between points $\mathrm{P}$ and $\mathrm{R}$. The best results were obtained in spring and summer. This is good news because spring and summer are the most important periods for phytoplankton growth. The higher errors, still always below $2.34{ }^{\circ} \mathrm{C}$, occur during winter and early spring when temperature does not limit phytoplankton growth as much as light.

Such comparison between different types of observed and simulated values is very rare, even more in small, shallow lakes. This result is promising for the accuracy of the simulation of ecological processes or of the diffusion of pollutant plume in a lake, for example from a storm water inlet. Internal waves are well reproduced by the model, in amplitude and in frequency. Such simulations were done on deeper lakes and larger reservoirs like Rappbode Reservoir, Germany [16], or Itumbiara Reservoir, Brazil [17], but as far as we know no modeling results exist on such a small, shallow lake.

In order to assess the model performances on Lake Créteil, we compared the outcomes in two complementary ways: (i) by comparing the values of the calibration coefficients to three other studies using Delft3D-FLOW on lakes and reservoirs of different morphologies and (ii) by comparing Lake Créteil performance indicators $\left(\mathrm{R}^{2}\right.$, MAE, RMSE) with those obtained with two different hydrodynamic models (EFCD and ELCOM) applied to shallow lakes of different sizes, all larger than Lake Créteil.

\subsection{Calibration Parameters}

The first comparison was done with the results of a study in Lake Constance, a large $\left(473 \mathrm{~km}^{2}\right)$ and deep perialpine lake of mean depth of $100 \mathrm{~m}$ and maximum depth of $254 \mathrm{~m}$ shared by Germany, Austria and Switzerland [18]. The second comparison was done with a study of Nam Theun 2 reservoir, a large and shallow reservoir of 506 $\mathrm{km}^{2}$, mean depth of $8 \mathrm{~m}$ and maximum depth of $35 \mathrm{~m}$ in Lao PDR []ㅡ. The third comparison was done with a study of Lake Yangchenghu, a large and shallow lake of $118 \mathrm{~km}^{2}$ in China, composed of three basins whose the mean depth are 1.7, 1.8, and $2.65 \mathrm{~m}$ [7]. We compared the model configuration between these three study sites and Lake Créteil (Tables 1and 2): (i) the turbulence model: background horizontal eddy viscosity, background horizontal eddy diffusivity of heat, background vertical eddy viscosity, background vertical eddy diffusivity of heat, Ozmidov length; (ii) the flow boundary conditions: wind drag coefficient; and (iii) the heat flux model: Dalton number, Stanton number, and coefficient for free convection.

In Lake Constance, Nam Theun 2 reservoir, and Lake Yangchenghu, the numbers of layers were respectively 50, 25 , and 10. A larger number of layers is needed to describe deeper lakes. 
For Lake Yangchenghu, as water temperature was not considered as a state variable, only the background horizontal eddy viscosity and the wind drag coefficient were compared. In these three water bodies, the background horizontal eddy viscosity are two or three orders of magnitude larger than in Lake Créteil because larger horizontal grids were used. In Lake Constance and in Nam Theun 2 reservoir, the background horizontal eddy diffusivity of heat was set to the same values as the background horizontal eddy viscosity and was also two or three order of magnitude larger than in Lake Créteil. This is coherent with the previous comparison. Background vertical eddy viscosity and diffusivity of heat were set to zero in Lake Créteil as well as Lake Constance and Nam Theun 2 reservoir. The Ozmidov length in Nam Theun 2 reservoir is set to zero like in Lake Créteil. These comparison results show that neither additional vertical mixing nor mixing around the thermocline is required. The latter is used in strongly stratified lakes with large internal waves.

Regarding the wind drag coefficient, a function of wind speed was used for Lake Constance [18]. This coefficient increases with the wind speed in order to take into account its influence in the surface roughness. In Lake Créteil, the fetch length is not such that large surface waves can form and increase the wind drag coefficient. The wind drag coefficient was set to 0.0005 for Nam Theun 2 reservoir [ㅁ] and 0.0025 for Lake Yangchenghu []]. This coefficient depends on the type of wind record and on the location of the meteorological station where wind speed was recorded. Wind speed measured at the meteorological station in Constance as representative data for the wind characteristics at $10 \mathrm{~m}$ height above lake surface was used for Lake Constance [18]. Both wind data computed by the model of the European Centre for Medium-Range Weather Forecasts (ECMWF) with a 6-h time step and measurements from two automatic meteorological stations located on the lake with a 10-min time step was used for Nam Theun 2 reservoir [6]. A constant wind speed of $3 \mathrm{~m} \mathrm{~s}^{-1}$ from wind data measured in the region around the lake was used for Lake Yangchenghu [7]].

Concerning the parameters involved in the heat flux budget, we used for Lake Créteil respectively 0.0015, 0.00145, and 0.14 for the Dalton and Stanton numbers and for the coefficient of free convection, close or equal to the default values. For Lake Constance, an increased Dalton number to 0.0021 was used and the Stanton number was kept to the default value of 0.00145 [18]. It can be supposed that the coefficient of free convection was set to zero because the Dalton number was very high. This could have been motivated by the fact that the wind rarely falls to zero on Lake Constance which means that loss of heat by free convection is negligible compared to forced convection. For Nam Theun 2 reservoir, slightly increased Dalton and Stanton numbers of 0.0016 were used [6]. Dalton and Stanton numbers depend also on the height above the surface of the meteorological station where air temperature and relative humidity are recorded. Nothing was said about the coefficient of free convection.

The comparison of the background horizontal eddy viscosity and diffusivity of heat confirmed that their values depend on the horizontal grid size and on the current intensity. For Lake Créteil, the wind drag coefficient and the Stanton and Dalton numbers are set to very close values, 0.0015 and 0.00145 . This indicates the reliability of the meteorological forcing and the accuracy of the surface heat budget and that spatially homogeneity of meteorological forcings can be assumed for lakes of this size.

\subsection{Performance of Three-Dimensional Hydrodynamic Models}

In our modeling results, the monthly mean absolute error (MAE) in water temperature ranges between 0.25 and $2.34^{\circ} \mathrm{C}$. The first comparison was done with the study of Lake Yilong using the Environmental Fluid Dynamic Code (EFCD) model [19]. Lake Yilong has a mean depth of $3.9 \mathrm{~m}$, a maximum depth of $5.7 \mathrm{~m}$, and a surface area of $28.4 \mathrm{~km}^{2}$. The hydrodynamic model was calibrated with data collected during 15 punctual campaigns over 1 year, from summer 2008 to summer 2009, at three monitoring points. During the calibration period the $R^{2}$ between measured and simulated water temperature (15 values), at the three monitoring points were $0.65,0.70$, and 0.74 .

The second comparison was done with the study of Lake Minnetonka using the Estuary and Lake Computer Model (ELCOM) [20]. Lake Minnetonka has a very complex morphology. The three studied parts of Lake Minnetonka have a maximum depth of 10,8.5, and $24 \mathrm{~m}$ for a total surface area of $8.01 \mathrm{~km}^{2}$. The calibration and the verification of the hydrodynamic model were performed using bi-weekly measured profiles of temperature at the deeper point of the three studied basins. The calibration was conducted with data collected between March 29 and October 20, 2000 (205 days) and the verification with data collected between April 25 and October 10, 2005 (168 days). The $R^{2}$ between measured and simulated water temperature of 12 bi-weekly profiles at the three stations ranged between 0.91 and 0.98 .

The third comparison was done with the study of Lake Okeechobee using an adapted version of the Environmental Fluid Dynamic Code (EFCD) model, Lake Okeechobee Environmental Model (LOEM) [211, 22, 23] . Lake Okeechobee is a very large and shallow lake. It has a mean depth of $3 \mathrm{~m}$ and a surface area of $1730 \mathrm{~km}^{2}$. During calibration between April 15, 1989 and June 14, 1989, the MAE and the RMSE of water temperature were 
respectively between 0.6 and $0.8^{\circ} \mathrm{C}$, and between 0.7 and $1.0^{\circ} \mathrm{C}$. During verifications between January 17,2000 and March 5, 2000 and between October 1, 1999 and September 30, 2000, the MAE and RMSE of water temperature were respectively between 0.4 and $0.9^{\circ} \mathrm{C}$, and between 0.5 and $1.3^{\circ} \mathrm{C}$.

The comparison of Delft3D-FLOW performance on Lake Créteil with other model application on small shallow lakes is not straightforward because as far we know, no comparable high-frequency data collected over nearly 2 years (21 months) of contrasting meteorological conditions were used for comparing to model results. The performance of the models EFCD on Lake Yilong and ELCOM on Lake Minnetonka were assessed using dataset based respectively on 15 and 12 campaigns, performed at three points. The $R^{2}$ between measured and simulated water temperature with Lake Créteil model is higher than for EFDC model on Lake Yilong and of the same level than for ELCOM model on Lake Minnetonka. The application of EFCD model on Lake Okeechobee gave the same range of RMSE and MAE values than on Lake Créteil.

\section{Conclusion}

For the first time, high temporal resolution data were used to assess the performances of the 3D hydrodynamic model Delft3D-FLOW in a small and shallow urban lake. The model was calibrated by comparing measurements and simulation results of water temperature and water velocity at three points and five depths. The values of performance indicators were also systematically calculated. The values of the calibration parameters were compared to literature values obtained for Delft3D-FLOW on lakes of different characteristics. This comparison showed the influence of the forcing data used on the calibration coefficient values but in general, a good agreement was found. The model was then verified during 18 other time periods between measurement campaigns over 21 months. It reproduced well the alternation of stratification and mixing and also the spatial vertical and horizontal heterogeneities of water temperature between the three monitored points in the lake. Its performances were compared to the literature. This comparison showed that our model set-up gives good results for Lake Créteil. The good results obtained during spring and summer, the key period for biological activity, will allow us to continue studying phytoplankton dynamics by coupling the water quality module, Delft3D-WAQ to Delft3D-FLOW.

\section{Acknowledgements}

The research presented in this paper was funded by grants from École des Ponts ParisTech, Région Île-de-France (research project PLUMMME), the Climate KIC (Blue Green Dream project), École doctorale SIE (Université Paris-Est). We acknowledge the French National Research Agency (ANR, research project PULSE) and the OSU EFLUVE for equiment funding. We also acknowledge the nke team for the sensor technical assistance and Département du Val de Marne, Ville de Créteil and Base de loisirs du lac de Créteil for their logical support in the field campaigns. The University of São Paulo (Brazil) supported the sabbatical stay of José R. Scarati Martins at Leesu/École des Ponts ParisTech. Finally we would like to thank Rob Uittenbogaard (DELTARES) and Frans Van de Ven (TU Delft) for fruitful discussions.

\section{References}

1.

Meybeck, M. (1995). Global distribution of lakes. In Lerman, A, Imboden, D, \& Gat, J (Eds.), Physics and chemistry of lakes (pp. 1-35). Berlin: Springer-Verlag.

2.

Downing, J., Prairie, Y., Cole, J., Duarte, C., Tranvik, L., Striegl, R., McDowell, W., Kortelainen, P., Caraco, N., Melack, J., \& Middelburg, J. (2006). The global abundance and size distribution of lakes, ponds, and impoundments. Limnology and Oceanography, 51(5), 2388-2397.

3.

Catherine, A., Troussellier, M., \& Bernard, C. (2008). Design and application of a stratified sampling strategy to study the regional distribution of cyanobacteria (Ile-de-France, France). Water Research, 42, 4989-5000.

4. 
Stepanenko, V.M., Martynov, A., Johnk, K.D., Subin, Z.M., Perroud, M., Fang, X., Beyrich, F., Mironov, D., \& Goyette, S. (2012). A one-dimensional model intercomparison study of thermal regime of a shallow turbid midlatitude lake. Geosci Model Dev Discuss, 5, 3993-4035.

\section{5.}

Medrano, E.A., Uittenbogaard, R.E., Pires, L.M.D., van de Wiel, B.J.H., \& Clercx, H.J.H. (2013). Coupling hydrodynamics and buoyancy regulation in Microcystis aeruginosa for its vertical distribution in lakes. Ecological Modelling, 248, 41-56.

\section{6.}

Chanudet, V., Fabre, V., \& van der Kaaij, T. (2012). Application of a three-dimensional hydrodynamic model to the Nam Theun 2 Reservoir (Lao PDR). Journal of Great Lakes Research, 38(2), 260-269.

7.

Zhu, Y., Yang, J., Hao, J., \& Shen, H. (2009). Numerical simulation of hydrodynamic characteristics and water quality in Yangchenghu Lake. Advances in Water Resources and Hydraulic Engineering, 1-6, 710715 .

8.

Fabian, J., \& Budinski, L. (2013). Horizontal mixing in the shallow Palic Lake caused by steady and unsteady winds. Environmental Modeling and Assessment, 18(4), 427-438.

9.

Kopmann, R., \& Markofsky, M. (2000). Three-dimensional water quality modelling with TELEMAC3D. Hydrological Processes, 14(13), 2279-2292.

10.

Garnier, J. (1992). Typical and atypical features of phytoplankton in a changing environment - 8 years of oligotrophication in a recently created sand-pit lake (creteil lake, paris suburb, france). Archiv Fur Hydrobiologie, 125(4), 463-478.

11.

Deltares. (2013). Delft3D-FLOW user manual. The Netherlands: Delft.

12.

Gill, A.E. (1982). Atmosphere-Ocean Dynamics (International Geophysics Series, Volume 30). Academic Press.

13.

Lane, A. (1989). The heat balance of the North Sea. Birkenhead, Proudman Oceanographic Laboratory, 46pp. Proudman Oceanographic Laboratory, Report No. 8.

14.

UNESCO. (1981). Tenth report of the joint panel on oceanographic tables and standards, Technical papers in marine science 36. Paris: France.

15. 
Taylor, K.E. (2001). Summarizing multiple aspects of model performance in a single diagram. Journal of Geophysical Research: Atmospheres, 106, 7183-7192.

16.

Bocaniov, S.A., Ullmann, C., Rinke, K., Lamb, K.G., \& Boehrer, B. (2014). Internal waves and mixing in a stratified reservoir:Insights from three-dimensional modeling. Limnologica - Ecology and Management of Inland Waters, 49(0), 52-67.

17.

Curtarelli, M.P., Alcantara, E., Renno, C.D., Assireu, A.T., Bonnet, M.P., \& Stech, J.L. (2014). Modelling the surface circulation and thermal structure of a tropical reservoir using three-dimensional hydrodynamic lake model and remote-sensing data. Water and Environment Journal, 28(4), 516-525.

18.

Wahl, B., \& Peeters, F. (2014). Effect of climatic changes on stratification and deep-water renewal in Lake Constance assessed by sensitivity studies with a 3D hydrodynamic model. Limnology \& Oceanography, 59(3), 1035-1052.

19.

Zhao, L., Li, Y.Z., Zou, R., He, B., Zhu, X., Liu, Y., Wang, J.S., \& Zhu, Y.G. (2013). A three-dimensional water quality modeling approach for exploring the eutrophication responses to load reduction scenarios in Lake Yilong (China). Environmental Pollution, 177, 13-21.

20.

Missaghi, S., \& Hondzo, M. (2010). Evaluation and application of a three-dimensional water quality model in a shallow lake with complex morphometry. Ecological Modelling, 221(11), 1512-1525.

21.

Jin, K.R., Hamrick, J.H., \& Tisdale, T. (2000). Application of three-dimensional hydrodynamic model for Lake Okeechobee. Journal of Hydraulic Engineering-Asce, 126(10), 758-771.

22.

Jin, K.R., Ji, Z.G., \& Hamrick, J.H. (2002). Modeling winter circulation in Lake Okeechobee, Florida. Journal of Waterway Port Coastal and Ocean Engineering-Asce, 128(3), 114- 125.

23.

Jin, K.R., \& Ji, Z.G. (2005). Application and validation of three-dimensional model in a shallow lake. Journal of Waterway Port Coastal and Ocean Engineering-Asce, 131(5), 213- 225. 